\title{
Compreensão de texto e desempenho acadêmico em estudantes de psicologia
}

\author{
Text comprehension and academic achievement \\ by psychology undergraduates
}

\author{
Elza Maria Tavares SILVA' \\ Geraldina Porto WITTER ${ }^{2}$
}

\begin{abstract}
Resumo
Objetivou-se estudar a compreensão de leitura e a sua correlação com disciplina específica e geral. Participaram 18 universitárias de Psicologia de escola privada, $5^{\circ}$ período. Um teste de Cloze convencional (total possível de acertos=40) foi aplicado no início do período letivo, e outro, no final. Colheram-se também avaliações da disciplina Leitura e Escrita e de uma prova diagnóstica. No pré-teste, a compreensão variou de 13 a 23 acertos, no pós-teste variou de 12 a 22 . Em Leitura e Escrita a variação foi de 6 a 9,5. Na diagnóstica, as notas foram de 5,5 a 9. Verificou-se correlação significativa $\left(p=0,05\right.$ adotado para o trabalho todo) entre compreensão de texto pré e pós $\left(r_{\circ}=0,51\right)$; entre avaliação acadêmica na disciplina específica e na diagnóstica $(r=0,32)$ não houve significância. Entre avaliação diagnóstica e pré-teste a correlação foi de 0,42 , e o pós-teste foi 0,38 . No todo, o teste $T$ resultou em $T=58(n=17)$, sendo $T_{c}=35$. Conclui-se que $H_{0}$ não foi rejeitada, pois não houve diferença entre as duas medidas. É possível também concluir que não houve melhoria em leitura e o nível em leitura não foi satisfatório.
\end{abstract}

Unitermos: Compreensão de leitura. Leitura. Teste de cloze.

\begin{abstract}
The aim was to study reading comprehension and its correlation with general and specific subjects in 18 women Psychology students from a private college. The conventional Cloze test (total possible score $=40$ ) was applied at the beginning and the end of the academic course. Evaluations conducted for the Reading and Writing course and one diagnostic test were also taken into consideration. In the pre-test, comprehension varied between 13 and 23 correct responses, while in post-test the range was from 12 to 22. In Reading and Writing, the results ranged from 6 to 9.5. In the diagnostic evaluation, the scores went from 5.5 to 9. The correlation between pre-and post-tests in reading comprehension was significant ( $p=0.05$ used in the whole study) $\left(r_{0}=0.51\right)$, but not so between the two subjects $(r=0.32)$. Diagnostic evaluation vs. pre-test was 0.42 and vs. post-test 0.38 . Overall, the T test was $58(n=17)$ with $T_{c}=35$. The $H_{0}$ was not rejected, as there was no difference between the two measurements. It is also possible to conclude that there was no improvement in reading and that the level of reading was not satisfactory.
\end{abstract}

Uniterms: Reading comprehension. Reading. Cloze testing.

$\boldsymbol{\nabla} \boldsymbol{\nabla} \boldsymbol{\nabla}$

1 Universidade de Mogi das Cruzes, Centro de Ciências Humanas, Curso de Psicologia. Av. Dr. Cândido Xavier de Almeida e Souza, 200, 08780-911, Mogi das Cruzes, SP, Brasil. Correspondência para/Correspondence to: E.M.T. SILVA. E-mail: <emts@terra.com.br>.

2 Universidade Camilo Castelo Branco. São Paulo, SP, Brasil. 
Como lembram Almeida e Soares (2004), a expansão do ensino superior abriu-se progressivamente para as camadas sociais mais heterogêneas, passandose a um "ensino de massa", mais democrático, mas com disfuncionamentos quanto aos que o freqüentam. Entre os problemas que emergiram está a falta de competência em leitura dos alunos que chegam à universidade. Ela dificulta tanto seu sucesso escolar como seu desenvolvimento psicossocial e profissional. Também se pode estar diante do que Gomes (2005) denominou "geração TV", que tem na mídia televisiva sua principal fonte de lazer e de informação, e não aprecia nem domina bem a leitura. Todavia, ler e escrever são atividades fundamentais para a vida na sociedade contemporânea. Vale lembrar que o texto é um meio muito popular de disseminar a informação e de educar (Snyman, 2004).

A compreensão do texto é essencial para que se possa dizer que realmente ele foi lido. Dessa forma, tratase de um tema muito freqüente entre os que pesquisam e os que trabalham com leitura, ou mesmo aqueles que são apenas leitores (Witter, 1996). Oliveira (1993) e Egypto (1983) comungam do mesmo pensamento ao afirmarem que a compreensão é imprescindível para que haja comunicação e para que se efetivem as relações autor-texto-leitor. Independentemente do referencial teórico, compreensão é um aspecto básico quando se enfoca a leitura.

Ao caracterizar o comportamento textual, Skinner (1957) explica que a compreensão implica em responder ao texto (autor) apreendendo o sentido que o escritor deu ao texto, considerando o contexto, tanto próprio como do autor, resposta complexa que envolve muitas cadeias e a história de vida do leitor.

Há relação entre leitura e escrita, e o contato com a última permite mais e mais o desenvolvimento da habilidade metalingüística, que, como apontado por Witter (1980), aproxima-se de um sistema em espiral que facilita o desenvolvimento de habilidades básicas em leitura e escrita, entre as quais se situa a compreensão.

Também há investigações realizadas nas quais se estudou a existência de relação entre desempenho em leitura e rendimento, assim como outros aspectos da vida acadêmica. Santos, Suehiro e Oliveira (2004) 396 encontraram correlações nesse sentido. Robinson,
Faraone, Hittleman e Unruh (1990) destacam a importância da leitura como um dos caminhos que levam o aluno ao acesso e à produção do conhecimento, enfatizando a leitura crítica como uma forma de recuperar todas as informações acumuladas historicamente, e de utilizá-las de maneira eficaz.

No Brasil, o trabalho de muitos pesquisadores tem como foco analisar o sujeito enquanto leitor, bem como identificar as habilidades e estratégias envolvidas na leitura, entendidas como fundamentais para o processo da compreensão nas diversas etapas da escolarização e, em especial, no ensino superior (Marini, 1986; Oliveira, 1993; Silva, 1998, 2002; Witter, 1997).

Alguns estudiosos brasileiros, cientes da importância da compreensão em leitura voltada para o bom desempenho acadêmico, têm realizado pesquisas sobre o tema, na tentativa de encontrar resultados confiáveis para fundamentar o diagnóstico das dificuldades de leitura compreensiva.

Certamente, entre as questões que permeiam a atuação de estudantes universitários está a sua competência para leitura (Joly, Santos \& Sisto, 2005), que requer o uso de estratégias, estilos cognitivos, motivação e muitas outras habilidades nem sempre desenvolvidas nos níveis precedentes de escolaridade. Este quadro parece agravar-se nas Instituições de Ensino Superior (IESs) particulares, para as quais se encaminha a maioria de alunos da escola pública.

No que concerne ao ensino superior, a leitura é o principal recurso de aprendizagem, e a última oportunidade formal para que o aluno se torne um leitor competente e possa ser um melhor cidadão e profissional. Também deve ter aprimorado a leitura crítica e criativa durante os anos universitários (Witter, 1997).

Assim, quando o aluno tem bom domínio da leitura é mais provável que também desenvolva atitudes mais positivas para esta atividade, tenha melhores condições de estudo e melhor aproveitamento acadêmico (Oliveira, Santos \& Primi, 2003; Santos et al., 2004). Vale relembrar que, em todas as disciplinas acadêmicas, grande parte do aprendizado se faz via leitura. Sendo uma competência básica, é importante a sua avaliação em todos os níveis de ensino. Isto tem apoio também no fato de que a avaliação da aprendizagem é um tópico que merece destaque em toda área acadêmica. Oliveira 
e Santos (2005) contam que o ato de avaliar é algo muito antigo, pois já no ano de 2205 a.C., um imperador chinês chamado Shun examinava seus oficiais com o fim preciso de promovê-los ou demiti-los. Porém, foi no século XIX, nos Estados Unidos, que o termo avaliação da aprendizagem alcançou sua especificidade e a difusão que hoje é observada.

Entretanto, como bem considera Assaf (2006), tanto professores quanto especialistas em leitura precisam estar atentos não apenas às características de mensuração dos instrumentos, pois eles podem se afastar muito da realidade da sala de aula e trazer mais problemas que soluções para o ensino-aprendizagem, às vezes com efeitos negativos na qualidade do ensino, quando apoiados estritamente nos resultados de avaliação.

Sobre esse assunto, Silva e Santos (2004) salientam a preocupação de muitos estudiosos da área em relação ao uso adequado de instrumentos de avaliação e indicam, no que concerne ao comportamento de ler, que: OTeste Cloze é um deles, pois busca uma mensuração da compreensão em leitura, enquanto fenômeno psicológico, possibilitando que as tomadas de decisões sejam as mais adequadas (p.461).

O Teste Cloze foi criado por Taylor, em 1953 (McKenna \& Robinson, 1980) com finalidades clínicas de diagnóstico e terapia no enfoque gestaltista, mas logo passou a ser usado como uma das formas confiáveis para avaliar a compreensão em leitura, fundamentandose em princípios gestálticos. As variações do Teste Cloze foram se consolidando na medida em que os estudos sobre esse teste avançaram, dependendo do objetivo pretendido (diagnóstico ou remediação da compreensão em leitura), sendo usado por estudiosos de enfoques teóricos diversos (Ferreira \& Griffin, 2003; Friedman \& Hoffman-Goetz, 2006). É um procedimento similar a outras práticas pedagógicas, o que recomenda o seu uso (Assaf, 2006).

Há estudiosos sobre o assunto (Abraham \& Chapelle, 1992) que consideram o Teste Cloze mais que um instrumento de avaliação da compreensão em leitura, porque possibilita o acesso aos processos de pensamento relacionados tanto à leitura quanto à escrita. Vale destacar que a proporção de acertos depende não só da habilidade em leitura de quem fazo teste, mas também da dificuldade criada pelas lacunas em razão da categoria gramatical suprimida, e também do assunto tratado no texto.

Atestam a validade do uso do Cloze para medir a compreensão pesquisas como as de Kusec et al. (2006), cujos resultados recomendam a aplicação deste procedimento para verificar a legibilidade de textos e a compreensão; essas pesquisas também destacam a importância ética de as pesquisas terem o consentimento livre e esclarecido dos participantes, uma vez que se está avaliando característica pessoal.

O nível de compreensão de leitura em universitários foi objeto de sete das pesquisas expostas na obra organizada por Witter (1997), e foi avaliado por meio da Técnica Cloze. O primeiro estudo é o de Wolff, Polimeno, Oliveira, Henriques e Socci (1997), que investigaram 60 alunos de uma universidade particular, todos do primeiro ano, sendo 20 do curso de Comunicação Social, 20 do curso de Educação Física e 20 do curso de Fonoaudiologia. Concluíram que, contrariando a literatura e a própria experiência docente, a amostra pesquisada apresentou índice de mediano a bom na escala de inteligibilidade proposta, com casos raros de baixo rendimento.

Centafanti, Ferreira e Tedesco (1997) avaliaram 54 alunos de Psicologia que se comportaram como bons leitores nas respostas dos textos em Cloze e, portanto, com repertório adequado para leitura. Chaguri, Barbosa, Arouca e Wuo (1997) pesquisaram 60 alunos do curso de Biologia de séries diferentes; verificaram que a influência da escolaridade estava sendo nula para os participantes da amostra pesquisada, fato este que contraria o que, em princípio, seria esperado, ou seja, que os alunos dos $4^{\text {os }}$ anos tivessem um desempenho significativamente melhor do que os de $1^{\text {os }}$ anos.

O estudo de Silva, Malozze e Leme (1997) foi realizado no curso de Direito com alunos iniciantes e concluintes. Os resultados demonstraram que os anos de escolaridade estão sendo deficitários para os participantes da amostra pesquisada. Por sua vez, Castro, Fukuda e Gritti (1997) fizeram sua pesquisa no curso de Letras e avaliaram iniciantes e concluintes. Também nesta pesquisa constatou-se que os anos de escolaridade não colaboraram significativamente para o desenvolvimento de uma leitura com compreensão crítica e independente. 
Pinto, Alvarenga e Kock (1997) pesquisaram alunos do curso de Matemática do $2^{\circ}$ ano e do último ano. Os resultados obtidos demonstraram que os alunos saíram-se melhor em compreensão de textos específicos, porém em relação ao texto geral mostraram certa dificuldade, apontando para o fato de que o ensino que recebem não tem privilegiado a formação generalista. A pesquisa feita por Gonçalves, Garcia e Pereira (1997), com 50 alunos do curso de Pedagogia, metade do primeiro ano e metade do terceiro ano, demonstrou que os participantes do terceiro ano apresentaram um melhor nível de compreensão de textos, o que evidenciou a eficiência, ainda que parcial, do sistema escolar universitário, que parece ter propiciado condições de melhoria do desempenho dos seus alunos.

Yamashita (2006) avaliou a compreensão do inglês entre estudantes universitários japoneses com capacidades distintas como leitores, e que se mostraram diferentes quanto ao uso da informação contida no texto para responder ao Teste Cloze, indicando que o teste tem alto poder discriminativo para medir capacidade de processamento. Também Chan (2003) usou o Teste Cloze para verificar entre universitários chineses a compreensão de texto em inglês, verificando que, no início, o fator cultural é importante na compreensão, mas, a partir do nível intermediário, já não afeta a compreensão.

Nota-se, assim, que o número elevado de pesquisas utilizando a técnica Cloze só vem corroborar a importância do diagnóstico da compreensão em leitura (Santos, 1990; Santos, 2004; Santos, Primi, Taxa \& Vendramini, 2002). E, no que concerne ao papel da universidade na avaliação dos alunos, Silva (2001) ressalta que a instituição deve assumir sua responsabilidade quanto ao fracasso ou sucesso do mesmo.

Dessa forma, pode-se destacar que o elemento que gerou este estudo foi a certeza de que a proposta de uma avaliação confiável da compreensão da leitura em universitários pode possibilitar o desenvolvimento de práticas educativas mais eficazes.

Considerando a relevância da leitura na formação universitária e na educação continuada do futuro profissional, foram estabelecidos os objetivos deste trabalho. O objetivo geral foi conhecer aspectos da compreensão de leitura em estudantes universitários de Psicologia. Como objetivos específicos, foram propostos: a) avaliar a compreensão de leitura de estudantes universitários de Psicologia matriculados no
50 período; b) verificar a sua correlação com o desempenho em disciplina específica de leitura e escrita; c) comparar o desempenho em compreensão no início e término de disciplina; d) correlacionar com uma avaliação diagnóstica, cobrindo todas as matérias acadêmicas do período; e) correlacionar os resultados entre si.

\section{Método}

\section{Participantes}

Serviram como sujeitos desta pesquisa 18 estudantes universitárias de um curso de Psicologia, do período noturno, todas do gênero feminino. A coleta incluiu todos os alunos da classe ( $n=39$ ), porém vários foram excluídos como participantes por não estarem presentes em uma das sessões de coleta. A idade das participantes variou de 19 até 32 anos; eram de classe média baixa ou baixa, e trabalhavam durante o período diurno. Todas freqüentavam o $5^{\circ}$ semestre do período noturno,

\section{Material}

Teste Cloze: O texto foi preparado na forma padrão, com o quinto vocábulo omitido mantendo-se o espaço correspondente à palavra omitida com dez toques, em um total de 40 omissões. Como é estabelecido pela técnica, o primeiro e o último parágrafos ficaram intactos. O texto completo correspondeu a uma página digitada em papel A4. Para o pré-teste foi usado um texto de Almeida (1992) sobre leitura. No pós-teste recorreu-se a outro texto extraído do mesmo livro. Tratase de textos narrativos sobre leitura destinados a docentes de ensino fundamental e médio, que devem ser facilmente compreensíveis para alunos universitários.

Termo de Consentimento Livree Esclarecido: esclarecendo os objetivos da pesquisa e o seu propósito, este termo solicitou formalmente a participação das alunas, garantindo sigilo absoluto quanto aos dados pessoais; assegurou às participantes desistir ou retirar seu consentimento quando desejassem, sem que isto implicasse em qualquer prejuízo.

Avaliação na disciplina Leitura e Escrita: a avaliação consistiu na média obtida pelas alunas na 
disciplina e incluiu: provas de alternativas, relatório do uso remediativo da técnica Cloze aplicada a crianças, seminários de vários tipos usando textos, e exercícios práticos realizados em classe e fora dela.

Avaliação diagnóstica: Trata-se de uma prova que cobre todas as disciplinas de Psicologia, Estatística, Biologia e Licenciatura ministradas no período, com duas ou quatro questões por disciplina, cuja média é uma avaliação global do desempenho dos alunos no semestre; trata-se de uma exigência do projeto pedagógico do curso.

\section{Procedimentos}

A pesquisa foi parte integrante do Projeto Prevenção de problemas biopsicossociais: atuação de profissionais, pesquisadores e de futuros profissionais. Trata-se de projeto aprovado pelo Comitê de Ética de Pesquisas com Seres Humanos (Processo 015/2005. CAAE 0005.0.237.000-05) da Universidade de Mogi das Cruzes.

Os alunos estavam matriculados na disciplina Leitura e Escrita, que integra seu currículo de Licenciatura. Foram devidamente informados do estudo. Esclarecidas as dúvidas, aplicou-se o Termo de Consentimento Livre e Esclarecido. Em seguida, foi aplicado o pré-teste, incluindo as instruções de como proceder para respondê-lo. Isso ocorreu no primeiro dia de aula.

Nas aulas que se seguiram foram dadas informações a respeito da Técnica Cloze (surgimento, criador, utilidade). Em seguida, as alunas foram instruídas a produzir um material, utilizando o Cloze, para ser aplicado a um aluno de série escolhida pela participante. 0 material foi elaborado individualmente ou em grupo ( $n=2$ alunos). A elaboração, aplicação e relatório requereram três meses aproximados de atividades, com aplicação semanal. Paralelamente, assistiram a aulas sobre o tema, leram, elaboraram material sobre as hierarquias de leitura, aprenderam técnicas diversas de seminários com textos, variáveis dos materiais, dos leitores, do contexto familiar e das tecnologias de ensino da leitura.

Fizeram uma prova sobre a matéria e a prova diagnóstica, em dias diferentes da semana do semestre. No último dia de aula, foi aplicado o pós-teste.

\section{Resultados}

A análise dos resultados está apresentada segundo os objetivos, começando com os dados relativos à compreensão. Entre as possibilidades de correção oferecidas pela técnica Cloze, optou-se por considerar como certa apenas a resposta igual à do texto original, seguindo a origem histórica de criação da Técnica Cloze, e face aos objetivos do trabalho. Uma apresentação gráfica dos dados aparece na Figura 1, expressando tanto o obtido no pré como no pós-teste, por sujeito.

No pré-teste ocorreram dois picos: o primeiro ficou em 21 acertos, equivalendo a 22\% dos participantes; o segundo recaiu em 17 acertos, também correspondendo a 22\% dos participantes. Verificou-se uma compreensão mediana por parte dos alunos, conforme toda a avaliação de Cloze constante na literatura, parte da qual aqui já foi citada, devendo, assim, ser mais bem trabalhada, seja por meio de textos específicos ou não. Certamente, muitos alunos poderiam ser beneficiados com um programa de remediação. Foi feita a sugestão, mas não tinham tempo disponível para comparecerem às sessões.

No pós-teste houve somente uma concentração, que recaiu nos 14 acertos, o que corresponde a $22 \%$ dos participantes. Levando-se em consideração o número de acertos total (40), observou-se que esses participantes apenas acertaram 35\% da compreensão do texto, fato preocupante por se tratar de alunos que já estão no $5^{\circ}$ semestre do curso; assim, aparentemente os anos de escolaridade pouco contribuíram para a leitura e a compreensão com proficiência. Para a interpretação do desempenho recorreu-se à conhecida e usada classificação de Bormuth (1968), recorrente em muitas pesquisas, como as que integram o livro de Witter (1997), para lembrar algumas nacionais. A aplicação dos critérios do referido autor mostram que, realmente, poucos par-ticipantes estão dentro da margem de leitura Instru-cional de Bormuth (21 a 26 pontos); a maioria ficou no nível da Frustração (3 a 20 pontos), ou seja, dependem de ajuda externa para entender o texto, sendo que nenhum se mostrou leitor Autônomo (27 ou mais pontos). Estes resultados assemelham-se aos referidos na introdução, em que os universitários tiveram desempenho aquém do esperado em curso superior. Os 
universitários devem ser leitores autônomos, ou seja, ter competência para plena compreensão do texto, ser críticos e não depender de qualquer ajuda no exercício da leitura (Cummins, 2006; Matheus \&Walker, 2006).

A fim de verificar se o desempenho dos participantes no pré e pós-testes estavam relacionados, utilizou-se a correlação por postos de Spearman, com base nos dados relativos aos totais de pontos obtidos ao responder aos dois textos. $O$ resultado foi de $r_{0}=0,97$, sendo a margem de erro aceita para pesquisa de $p \leq 0,05$ e $r_{c}=0,55$; este dado indica que houve correlação de compreensão em leitura no pré e pós-testes. Vale dizer que se manteve a hierarquia entre os leitores (Siegel, 1956), o que é obtido pela análise estatística, como é do conhecimento comum decorrente do teste. Também é importante lembrar que a correlação alta obtida mostra que foi estável a posição relativa dos sujeitos nas duas situações.

Na Figura 1, verifica-se que oito alunos (44\%) progrediram entre o pré e o pós-teste. Para verificar se a diferença de um desempenho do pré para o pós-teste foi significativa, recorreu-se ao teste $t$ de Wilcoxon, sendo 17 o número de sujeitos, $p \leq 0,05, H_{0}$ : pré e pós e $H_{a}$ : pré<pós. Já que, embora não tenha sido introduzido qualquer treino específico para melhoria da compreensão, os alunos estavam assistindo a um curso sobre leitura, era de se esperar que progredissem na leitura ao longo dos anos acadêmicos. Frente a estes parâmetros, obteve-se $T_{c}=35$ e $T_{0}=58$, podendo-se concluir que $\mathrm{H}_{\circ}$ não foi rejeitada; vale dizer que não houve diferença que alcançasse o nível de significância pré-estabelecido. Estes resultados podem ter decorrido também do fato de no pós-teste a coleta ter ocorrido no último dia de aula, e muitos alunos já haviam alcançado a nota exigida para uma aprovação direta. Além disso, muitos estavam sobrecarregados com tarefas de outras disciplinas.

Para uma melhor visualização, foi feita a representação gráfica das notas obtidas na matéria específica de leitura e escrita e a da avaliação diagnóstica, que estão na Figura 2. A partir dos dados expressos na Figura 2, foi feita a correlação para verificar o desempenho em compreensão de leitura por universitários de Psicologia; optou-se por fazer uma comparação primeira entre os resultados obtidos no pré-teste com as notas da matéria específica (leitura/escrita). A comparação feita utilizando

$\mathbf{4 0 0}$ a correlação por postos de Spearman mostrou que

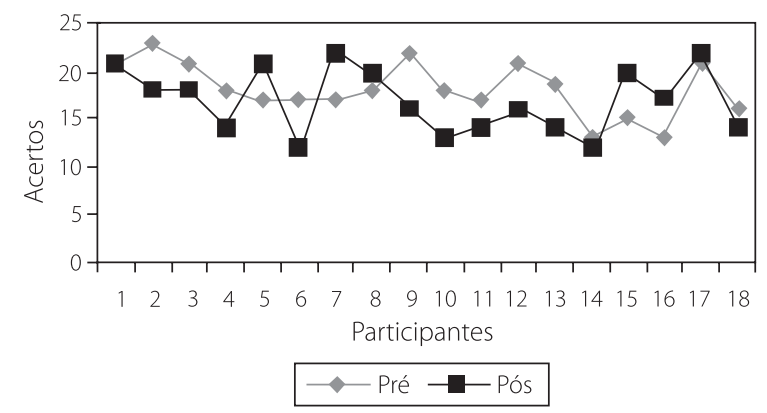

Figura 1. Número de acertos em compreensão de texto pelos participantes: pré e pós-testes.

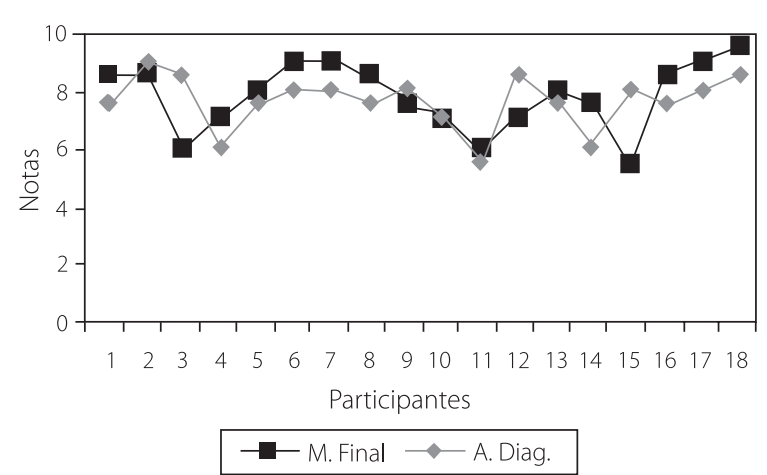

Figura 2. Desempenho em matéria específica leitura e escrita e avaliação diagnóstica.

houve correlação, pois r =0,96 entre pré-teste e média final da matéria específica de leitura e escrita, dentro dos parâmetros já especificados. A comparação feita entre os acertos obtidos no pós-teste com a matéria específica mostrou que houve correlação $\left(r_{0}=0,97\right)$, demonstrando que é significativa, já que $r_{c}=0,55$.

Porém, na comparação do pré-teste com as notas obtidas na avaliação diagnóstica, verificou-se que esta não foi significativa, com r $=0,44$. Na comparação do pós-teste com as notas da avaliação diagnóstica, o resultado também demonstrou que não alcançou significância, sendo o r =0,44. Pode ter influído aqui a ampla variedade de conteúdo abrangido por esta prova.

\section{Discussão}

De um modo geral, os dados obtidos indicam que a leitura é uma questão presente na vida do uni- 
versitário, como se depreende também de obras como a de Joly et al. (2005), mas que nem sempre vem sendo devidamente realizada, especialmente no que concerne à compreensão, aspecto essencial para que se possa dizer que realmente ocorreu a leitura.

Os resultados mostram que, no presente curso, está-se predominantemente trabalhando com leitores no nível de Frustração. Aliás, este resultado tem sido encontrado por outros pesquisadores que enfocam o problema em universitários brasileiros (Guerra, 2003; Oliveira, 2003; Witter, 1997). Muitas são as possíveis causas deste quadro; entre elas, podem ser lembradas: deficiências nos níveis do ensino fundamental e médio, desconhecimento ou uso inadequado de estratégias de aprendizagem e de leitura, baixa auto-eficácia, falta de autocontrole, desatenção, falta de concentração, vocabulário insuficiente, entre outras.

Há necessidade de se trabalhar melhor a leitura de textos informativos e técnicos nos anos anteriores à universidade (Saul \& Dieckman, 2005), o que não ocorre no Brasil, onde, quando há aulas de leitura, elas se limitam aos textos literários, e apenas nos primeiros anos do ensino fundamental. No exterior, aos poucos, os professores do ensino fundamental, médio e superior estão sendo preparados para capacitar o aluno a ler textos informativos, científicos e técnicos. Movimento similar precisa ocorrer no Brasil.

Embora sem diferença dentro do nível de significância estabelecido, e mantido o baixo nível de desempenho, o resultado um pouco pior no pós-teste pode estar relacionado ao cansaço inerente ao último dia de aula, pressa em sair da escola, festejos concomitantes (festas juninas, festas de despedida do semestre, festa do Divino Espírito Santo e outras) de final de semestre. Mas as variáveis essenciais que estão na raiz do problema não são estes fatos acidentais relacionados ao término do semestre. Certamente muitas pesquisas precisam ser feitas para que se possa ter um diagnóstico mais preciso. Entretanto, pode-se considerar que os resultados permitem inferir que o ensino nos níveis fundamental e médio não está formando leitores competentes, e que isto se reflete na Universidade - que, por sua vez, precisa usar de estratégias e programas específicos.

Os resultados de Oliveira e Gargantini (2005a), que também pesquisaram calouros de psicologia e de fonoaudiologia, usando a mesma tecnologia (Cloze convencional) em texto específico, embora ligeiramente superiores aos apresentados aqui, também mostram carências de desenvolvimento nas habilidades de leitura por muitos alunos. Parece evidente também a necessidade de verificar como professores universitários estão usando a leitura, seja enquanto leitores ou docentes (Oliveira \& Gargantini, 2005b), pois provavelmente essas duas faces podem estar afetando o evoluir do universitário como leitor.

Os resultados indicam ainda a necessidade de programas tanto preventivos como remediativos, os quais, por sua vez, devem ser objeto de pesquisas avaliativas. Há necessidade de ação interdisciplinar. Recorrer apenas ao ensino da língua é ineficaz quando se enfoca o assunto aqui relatado; o mesmo pode ser dito de cursos sobre a leitura e a escrita. Uma sugestão seria testar a eficiência de instrução de leitura usando algumas das diversas tecnologias e modelos de eficiência já comprovados cientificamente em outras realidades (Tyner \& Green, 2005).

Subjacente à falta de correlação com a avaliação nas disciplinas pode estar o próprio desempenho em leitura, a pouca cobrança de leitura e uma aprendizagem mais apoiada na informação oral apresentada na aula pelo professor, o que não é recomendável para maximizar o conhecimento e desenvolver competências (Matheus \& Walker, 2006).

Também é evidente a necessidade de os professores de todas as disciplinas gostarem de ler (Gomez, 2005) e saberem usar tecnologias que viabilizem o desenvolvimento das competências em leitura e da motivação do aluno para ler (Kelly \& Clausen-Grace, 2006; Parr \& Maguiness, 2005; Walmsley, 2006).

\section{Conclusão}

Os dados obtidos permitem algumas conclusões específicas sobre os resultados, que devem ser consideradas dentro dos limites da própria pesquisa, cujo total de participantes foi pequeno, pois foi realizada em sala, requerendo cautela na generalização dos resultados.

O teste Cloze mostrou-se mais uma vez um instrumento adequado para avaliar a compreensão em leitura. Quando foram focalizados os dados do pré e 
pós-testes, observou-se que as participantes apresentaram melhor desempenho no pré-teste, mas sem diferença significativa dentro da margem de erro da pesquisa. Vale dizer que o instrumento mostrou estabilidade no desempenho das alunas. Também ficou evidente que só ler e assistir aulas sobre o tema leitura é insuficiente para mudar o desempenho dos alunos. É necessário promover estratégias específicas e treino regular para que mude a competência em compreensão de texto.

Verificou-se que o desempenho em termos de acertos (Figuras 1 e 2) ficou aquém do esperado para alunos universitários. Dessa forma, constata-se mais uma vez que é necessário utilizar estratégias para desenvolver a compreensão em leitura, e esta deve ser sistemática, em todos os anos e em todas as matérias, tendo por base a literatura, inclusive a aqui referida anteriormente. O desempenho de algumas alunas é indicativo da necessidade de submetê-las a um programa especial de remediação.

As correlações encontradas entre pré e pós-teste e a nota na matéria específica de leitura e escrita não alcançaram significância, o mesmo ocorrendo com a nota da avaliação diagnóstica. São indícios de que o simples fato de estarem informadas sobre os vários aspectos da leitura foi insuficiente para tornar as alunas mais competentes em leitura. É necessária uma programação de competências específicas.

Também não se deve esquecer que a leitura, como atividade significativa que é, não pode ser entendida sem que se leve em consideração a participação do sujeito, possuidor de uma história individual e singular, e seu convívio tanto familiar quanto em sociedade, bem como na Academia. Há que se dar preparo adequado aos alunos para lerem textos técnico-científicos, e aos professores, para capacitá-los a formarem bons leitores.

Como em outros trabalhos nacionais, os resultados sugerem a necessidade de maior cuidado com a leitura nas fases anteriores de ensino, para que os alunos, ao entrarem na universidade, o façam como leitores competentes. Se isto não ocorre é preciso prever programas de remediação para universitários.

\section{Referências}

Abraham, R. G., \& Chapelle, C. A. (1992). The meaning of cloze test scores: an item difficulty perspective. The Modern Language Journal, 76 (3), 468-479.
Almeida, N. (1992). Malhas \& magias. São Paulo: ReconstruçãoEducação, Assessoria e Pesquisa.

Almeida, L. S., \& Soares, A. P. (2004). Os estudantes universitários: sucesso escolar e desenvolvimento psicossocial. In E. Mercury \& S. A. J. Polydoro (Orgs.), Estudante universitário: características e experiências de formação (pp.15-40). Taubaté: Cabral Editora.

Assaf, L. (2006). One reading specialist's response to high-stakes testing pressures. The Reading Teacher, 60 (2), 158-167.

Bormuth, R. J. (1968). Cloze test readability: criterion reference scores. Journal of Educational Measurement, 5 (1), 169-189.

Castro, C. A. S., Fukuda, M., \& Gritti, N. H. S. (1997). Compreensão de leitura entre universitários de curso de Letras (10 e $4^{\circ}$ anos). In G. P. Witter (Org.), Psicologia leitura e universidade (pp.11-122). Campinas: Alínea.

Centafanti, E. M., Ferreira, S. M., \& Tedesco, T. D. (1997). Compreensão de leitura por universitários de Psicologia. In G. P. Witter (Org.), Psicologia leitura e universidade (pp.33-60). Campinas: Alínea.

Chaguri, A., Barbosa, B. A., Arouca, E. A., \& Wuo, M. (1997). Compreensão de leitura: estudo comparativo entre universitários. In G. P. Witter (Org.), Psicologia leitura \& universidade (pp. 61-76). Campinas: Alínea.

Chan, C. Y. H. (2003). Cultural content and reading proficiency: a comparison of Mainland Chinese and Hong Kong learners of English. Language, Culture and Curriculum, $16(1), 60-90$.

Cummins, C. (Org.) (2006). Understanding and implementing reading first initiatives: the changing role of administrators. Newark: IRA.

Egypto, M. S. R. (1983). Leitura em estudantes universitários: estudo contrastivo de caracterização de nível de desempenho. Dissertação de mestrado não-publicada, Universidade Federal do Paraíba, João Pessoa.

Ferreira, V. S., \& Griffin, Z. M. (2003). Phonological influences on lexical (mis) selection. Psychological Science, 14 (1), 86-90.

Friedman, D. B., \& Hoffman-Goetz, L. (2006). A systematic review of readability and comprehension instruments used for print and Web-based cancer information. Health Education \& Behavior, 33 (3), 352-373.

Gomes, K. (2005). Teachers of literacy, love of reading and the literate self: a response to Ann Powell-Brown. Journal of Adolescent and Adult Literacy, 49 (2), 92-96.

Gonçalves, E. S. G., Garcia, I. G., \& Pereira, R. P. F. (1997). Compreensão de leitura por calouros e terceiranistas de Pedagogia. In G. P. Witter (Org.), Psicologia, leitura e universidade (pp.181-190). Campinas: Alínea.

Guerra, P. B. C. (2003). Avaliando barreiras à criatividade e compreensão de leitura em universitários ingressantes. Dissertação de mestrado não-publicada, Universidade São Francisco, Itatiba.

Joly, M. C. R. A., Santos, A. A. A., \& Sisto, F. F. (2005). Questões do cotidiano universitário. São Paulo: Casa do Psicólogo.

Kelley, M., \& Clausen-Grace, N. (2006). R5: the sustained silent reading makeover that transformed readers. The Reading Teacher, 60 (2), 148-156. 
Kusec, S., Oreskovic, S., Skegro, M., Korolija, D., Busic, Z., \& Horzic, M. (2006). Improving comprehension of informed consent. Pattent Education and Counseling, 60 (3), 294-300.

Marini, A. (1986). Compreensão da leitura no ensino superior: teste de um programa para treino de habilidades. Tese de Doutorado não-publicada, Universidade Federal de São Paulo.

Matheus, J. R., \& Walker, C. E. (2006). Your practicum in Psychology: a guide for maximizing knowledge and competence. Washington, DC: APA.

McKenna, M. C., \& Robinson, R. D. (1980). An introduction to the Cloze procedure. Newark: IRA.

Oliveira, M. H. M. A. (1993). A leitura do universitário: estudo comparativo entre os cursos de engenharia e fonaudiologia da PUC-Campinas. Dissertação de mestrado não-publicada, Pontifícia Universidade Católica de Campinas.

Oliveira, M. H. M. A. , \& Gargantini, M. B. M. (2005a). Avaliação do desempenho de leitura em universitários. In M. H. M. A. Oliveira \& M. B. M. Gargantini (Orgs.), Tópicos em leitura-escrita: pesquisa e prática (pp. 33-45). São José dos Campos: Pulso Editorial.

Oliveira, M. H. M. A., \& Gargantini, M. B. M. (2005b). Professor universitário e leitura profissional. In M. H. M. A. Oliveira \& M. B. M. Gargantini (Org), Tópicos em leitura-escrita: pesquisa e prática (pp.47-59). São José dos Campos: Pulso Editorial.

Oliveira, K. L., \& Santos, A. A. A. (2005). Avaliação da aprendizagem na universidade. Psicologia Escolar e Educacional, 9 (1), 37-46.

Oliveira, K. L. (2003). Desempenho acadêmico e avaliação da aprendizagem em universitários. Dissertação de mestrado não-publicada, Universidade São Francisco, Itatiba.

Oliveira, K. L., Santos, A. A. A., \& Primi, R. (2003). Estudo das relações entre compreensão em leitura e desempenho acadêmico na Universidade. Interação, 7 (1), 19-25.

Parr, J. M., \& Maguiness, C. (2005). Removing silent from SSR: voluntary reading as social practice. Journal of Adolescent and Adult Literacy, 49 (2), 98-107.

Pinto, C. J. A., Alvarenga, M. A. P., \& Koch, R. A. A. (1997). Hábitos de leitura e compreensão de texto entre universitários. In G. P. Witter (Org.), Psicologia leitura e universidade (pp.133-166). Campinas: Alínea.

Robinson, H. A., Faraone, V., Hittleman D. R., \& Unruh, E. (1990). Reading comprehension instruction. Newark, DE: International Reading Association.

Santos, A. A. A. (1990). Compreensão em leitura na universidade: um estudo comparativo entre dois procedimentos de treino. Estudos de Psicologia (Campinas), 7 (1), 39-53.

Santos, A. A. A. (2004). A avaliação da compreensão em leitura e o desempenho acadêmico de universitários. Psicologia em Estudo, 9 (3), 459-467.

Santos, A. A. A., Primi, R., Taxa F., \& Vendramini C. M. M. (2002). O Teste de Cloze na avaliação da compreensão em leitura. Psicologia: Reflexão e Crítica, 15 (4), 549-560.

Santos, A. A. A., Suehiro, A. C. B., \& Oliveira, K. L (2004). Habilidades em compreensão da leitura: um estudo com alunos de psicologia. Estudos de Psicologia (Natal), 2 (2), 29-42.

Saul, E. W., \& Dieckman, D. (2005). Choosing and using information trade books. Reading Research Quarterly, 40 (4), 502-513.

Siegel, S. (1956). Non parametric statistics. New York: MacGraw-Hill.

Silva, E. M. T., Malozze, G. L. M., \& Leme, M. L. C. S. (1997). Compreensão de leitura entre universitários do primeiro e quinto anos de Direito. In G. P. Witter (Org.), Psicologia leitura e universidade (pp.101-110). Campinas: Alínea.

Silva, E. M. T. (1998). Compreensão da leitura em estudantes de Direito. Dissertação de mestrado, não-publicada, Pontifícia Universidade Católica de Campinas.

Silva, E. M. T. (2002). Compreensão da leitura, competência na escrita em alunos de Direito. Tese de doutorado nãopublicada, Pontifícia Universidade Católica de Campinas

Silva, M. J. M., \& Santos. A. A. A. (2004). A avaliação da compreensão em leitura e o desempenho acadêmico de universitários. Psicologia em Estudo (Natal), 9 (3), 459-457.

Silva, Z. B. (2001). O processo avaliativo na aprendizagem baseada em problemas: um estudo com alunos de medicina. Dissertação de mestrado não-publicada, Universidade de São Paulo.

Skinner, B. F. (1957). Verbal behavior. New York: Appleton.

Snyman, M. (2004). Using printed medium to disseminate information about psychiatric disorders. South Africa Psychiatry Review, 7 (4), 15-20.

Tyner, B., \& Green, S. E. (2005). Small group reading instructuion. A differentiated teaching model for intermediate readers. Grades 3-8. Newark: IRA.

Walmsley, S. A. (2006). Getting the big idea: a neglected goal for reading comprehension. The Reading Teacher, 60 (3), 281-285.

Witter, G. P. (1996). Educação no dissertation abstract international - 1992. Revista da Faculdade de Educação da USP, 22 (1), 193-208.

Witter, G. P. (1997). Leitura e universidade. In G. P. Witter (Org.), Psicologia: leitura e universidade. (pp.9-18). Campinas: Alínea.

Witter, G. P. (1980). O pré-escolar: um enfoque comportamental. São Paulo: Pioneira.

Wolff, A. C. R., Polimeno, E., Oliveira, E. T. A., Henriques, T., \& Socci, V. (1997). Compreensão da leitura em estudantes de comunicação social, educação física e fonoaudiologia. In G. P. Witter (Org.), Psicologia leitura \& universidade (pp.19-32). Campinas: Alínea.

Yamashita, J. (2003). Processes of taking a gap-filling test: comparison of skilled and less skilled EFL readers. Language testing, 20 (3), 267-293.

Recebido em: 25/5/2006

Versão final reapresentada em: 6/10/2006

Aprovado em: 24/11/2006 